\title{
A Collaboratively-Developed Enterprise Resource Planning (CD-ERP) Approach in Libyan Higher Education
}

\author{
Tareq Salahi Almigheerbi, David Ramsey, and Anna Lamek
}

\begin{abstract}
Like other HE institutes in the world, Libyan universities have continuously been working on developing their own ISs or adopting commercial solutions. Both models have shown negative results to some degree. This research was aimed, therefore, to introduce a new model, called: Collaboratively-Developed Enterprise Resource Planning (CD-ERP) to be applied in Libyan Higher Education (LHE). Generally, the model is based on two main principles: ERP packages and community-source. This study comes as the conclusion to a series of studies in a project to assess the CD-ERP model. After investigating the applicability of this model in the Libyan context, a CD-ERP model for LHE is proposed in this paper, including: the business model of the consortium, cloud architecture, alongside several recommendations for successful and efficient transformation from the current systems to the CD-ERP model.
\end{abstract}

Index Terms-Collaboratively-developed IS, ERP, cloud-computing, multi-tenancy, community-source, Libyan Higher Education (LHE).

\section{INTRODUCTION}

As a developing country, Libya is struggling to invest more in information and communication technology (ICT) in many sectors. The higher education (HE) sector is one vital segment that needs a significant upgrading of information technology (IT). Using IT effectively in HE is considered to be a highly practical method of enhancing its performance. The issue of information system (IS) development is a crucial part of ICT [1], [2]. To deal with the issue of IS development, universities worldwide face the decision of whether to build their own system or outsource its development to a third party. Alternatively, many projects in the HE sector have followed the principle of community-source. Community-source (referred to as the collaborative development approach in this research) can be defined as a type of open source project that is governed by a consortium of educational institutions [3]. Also, the ISs currently used in Libyan universities are often outdated and should be replaced. It is a costly task to rebuild ISs from scratch. ERP was hence included in this model to avoid such a problem.

The research question of this study is "What form of CD-ERP is suited to the size and needs of Libyan universities, and the requirements of HE planners at national level?" To

Manuscript received September 10, 2019; revised February 29, 2020.

Tareq Salahi Almigheerbi is with University of Tripoli, Tripoli, Libya. He is also with Wrocław University of Science and Technology, Wrocław, Poland (e-mail: t.almigheerbi@uot.edu.ly).

David Ramsey and Anna Lamek are with Wrocław University of Science and Technology, Wrocław, Polandx (e-mail: david.ramsey@pwr.edu.pl, anna.lamek@pwr.edu.pl). answer this question, a CD-ERP model is proposed after investigating the Libyan context, international experiences, and a literature review. This paper is organized into 6 sections. Section I provides an introduction to the study. The theoretical framework of the study is discussed in Section II. Section III provides the background to the subject of the study including: a definition of the model, related studies, and findings from previous studies carried out by the research team. Section IV presents the CD-ERP model and its structure. A summary of the study, limitations, and constraints is provided in Section V. Section VI concludes the study with recommendations and directions for future work.

\section{THEORETICAL FRAMEWORK}

The theoretical framework provides a scientific justification for a study. This section presents the framework used in order to gain the information required to propose a suitable approach to the development of ISs in LHE. In order to formulate the CD-ERP Model for LHE, the applicability of CD-ERP in LHE was questioned by conducting a series of studies, as shown in Fig. 1. Firstly, a deductive approach was followed, in which a literature review was used to draw conclusions about the core elements of the CD-ERP model. Secondly, lessons learnt from similar projects (referred to as international experiences) were included. Thirdly, an inductive approach was followed to study the Libyan context by conducting three case studies of Libyan universities. Based on the findings from these studies, the CD-ERP Model is constructed.

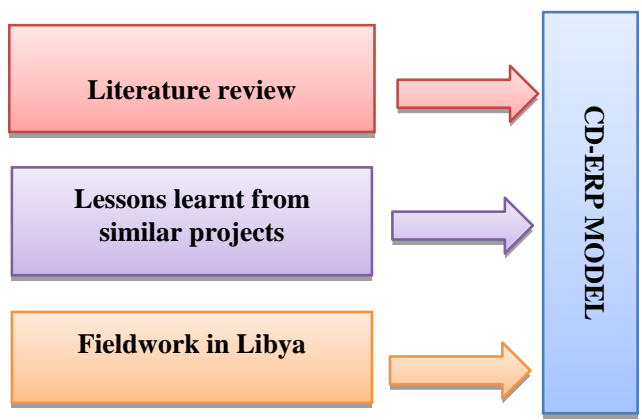

Fig. 1. Theoretical framework of the study

\section{BACKGROUND}

\section{A. The Concept of Collaborative-Development}

"Community-based open source" is also described in short as "community-source", while in this research it is called "collaborative development". It was first proposed by Brad 
Wheeler and defined as a type of open source project which is governed by a group of educational institutions or even firms [3]. In a community-source project, a consortium of partners share their financial efforts and human resources to complete a project. Such projects are managed through a defined form of consortium governance [4]. In particular, CD-ERP is a new model of software development which is intermediate between two well-known models (closed- and open-source systems).

\section{B. Related Studies}

The applicability of the CD-ERP model to LHE was studied by examining both international experiences and the Libyan context. To our knowledge, this study is the first to deal with both sides. Little attention has been paid to international experiences of the community source approach. The studies that have been carried out on these projects generally regard their technical issues, rather than the consortium itself. Consortiums between universities have existed for a long time, e.g. the CINECA project in Italy [5], [6] which dates back to 1969 , while the community-source paradigm was first applied by the KUALI [7] and SAKAI projects [8]-[10] in the United States. Similar projects have been implemented in Europe, Asia, and Africa, including; USOS in Poland [11], [12], the Sigma Suite and the CRIS Argos Suite in Spain [13], [14], FS University Consortium in Norway [15], [16], the AMUE system in France [17], Ladok in Sweden [18], and HisinOne in Germany [19], [20]. Other projects include development work on Sakai at both Cambridge and Oxford in the UK, and KUALI at Strathmore University in Kenya, JISC and UCISA in the UK, Surf in the Netherlands, AXIES in Japan, ASAUDIT in South Africa, and CUCCI in Canada [3], [4], [21].

The CD-ERP model presented here follows the principle of community-source in a similar way to those projects. However, our model differs, since it is based on ERP. Indeed, all of the projects mentioned have built integrated ISs based on existing codes/systems, e.g. the HisinOne project [20]. The fieldwork in Libya has indicated that the level of the ISs implemented in Libyan universities is very low and there is also a lack of capabilities for IS development. Moreover, it is challenging to integrate certain projects (for example, Sakai) with other enterprise software systems, such as ERP [22]. Therefore, the CD-ERP model is based on ERP, in order to avoid building integrated ISs from scratch and achieve faster and more reliable results. On the Libyan side, Bakeer has investigated the deployment of ISs in Libyan universities with an emphasis on the University of Misurata [23]. These studies neither discussed the development of ISs in Libyan universities as a whole, nor suggested any solutions. In contrast, this study proposes a solution to the issue of developing ISs by introducing the community-source approach as represented by the CD-ERP model.

\section{Findings from Previous Work}

This section presents some of the results of previous studies related to the applicability of the CD-ERP model. As mentioned earlier, three main data sources were used to construct a CD-ERP model: a literature review, the lessons learned from similar projects and results from fieldwork in
Libya. Although some failures of ERP systems have been ascribed to their complexity and the high-costs of implementation, it has been observed that most of the problems with ERP systems are more related to administrative issues than technical problems. This indicates that ERP software itself does not lead to unsuccessful implementation [24], [25]. Also, international experiences indicate that it is beneficial to build a system on existing code that works at least fairly well. Some cases of international projects have faced difficulties integrating their systems with ERP packages. Libyan universities would, therefore, benefit from adopting ERP-based solutions and not having to build their systems from scratch.

Concerning collaborative development, the findings have indicated that many benefits can be gained through following such an approach. For instance, following this approach is predicted to enable higher productivity and quality at lower cost, create a pool of locally available skilled resources, create leading-edge infrastructures and gather statistics from all $\mathrm{HE}$ institutes at national level under the Ministry of Education [26], [27]. Despite its difficulties, collaborative development has been adopted by many universities and government bodies worldwide. Also, HE is a sector based on knowledge sharing and the collaborative-development approach is described as a "perfect fit" for HE. Indeed, collaborative development can be viewed as a means of knowledge sharing, alongside other means of sharing, such as sharing costs or human resources. Additionally, the fieldwork in Libya has indicated that cooperation in IT has already been established between Libyan public universities. Indeed, some Libyan universities have adopted ISs which were developed by leading universities in Libya, such as the University of Tripoli and University of Benghazi.

Another term used in the proposed model is "Cloud computing" (CC). CC was added to the CD-ERP model, since it represents a great benefit to $\mathrm{HE}$, especially when universities intend to work jointly. The growing interest in $\mathrm{CC}$ within the HE sector could be a result of many factors, including the possibly of cost sharing [28]. Although security matters are a challenge, there is no absolute failsafe method providing security or data protection in any system. Higher Education Institutes (HEIs) have to overcome their fears. Furthermore, as CC already has a relatively long history, there are well-known service providers, as well as practices and models for CC. This helps minimize the risks and creates conditions for efficient and secure activities in the Cloud. In fact, some risks associated with CC could be alternatively viewed as benefits, such as: storing data and applications in $\mathrm{CC}$ will definitely save them in the case of a disaster. Also, due to the high level of protection in $\mathrm{CC}$, data and applications are often better protected than on companies' local servers [28]. However, developing a Cloud architecture for HEIs may be challenging and must take the following into consideration: the purpose and infrastructure of the institution itself; and national rules and regulations [29].

Moreover, multi-tenancy allows a variety of organizations to securely take advantage of a single application, which reduces costs and increases operational efficiency, while various degrees of isolation or sharing could be implemented. There are a number of reasons why multi-tenancy 
architecture is part of the CD-ERP model. First of all, many of the challenges of adopting multi-tenancy architecture, such as security, regulations or scalability, come from gathering completely different organizations into one project. Libyan universities are organizations which share common characteristics and, in particular, are geographically clustered. Also, a central organization (the Libyan Ministry of Education) delivers common services to multiple IT sub-departments (of Libyan universities) that also have autonomous portfolios for service delivery. It seems natural that these universities would benefit by sharing management, infrastructural and application development costs by adopting a multi-tenancy architecture [28], [29]. Also, in the case a university requiring a custom user interface with a unique brand or logo, multi-tenant applications are configurable in this way. In particular, customizations can be implemented during runtime, since the source code does not need to be modified. This, in return, ensures that the updates by ERP vendors would run smoothly.

\section{THE CD-ERP MODEL}

To answer the research question, the authors provide the proposed CD-ERP Model, including: the proposed model of collaboration, the business model of the consortium, the consortium structure (governance model), the CC architecture and several recommendations embedded for successful and efficient transformation from the traditional system into a CD-ERP system.

\section{A. Overview}

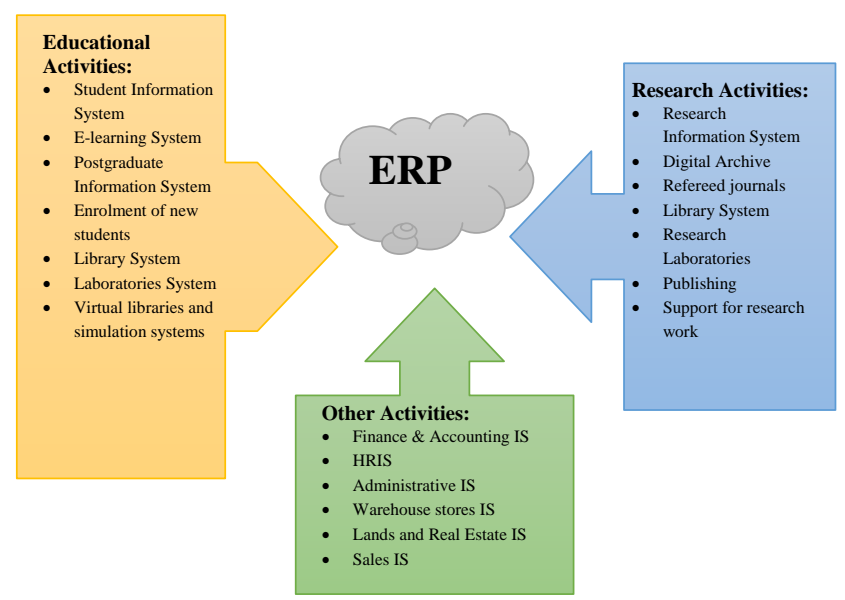

Fig. 2. Cloud ERP for HE institutes (Authors' own work, activities were classified on the basis of the model of business activities in HE institutes presented by [30].

The name of the Model: Collaboratively-Developed, Cloud-Based Multi-Tenant ERP Systems (in short: CD-ERP)

Definition of the model: CD-ERP is a model of software development which is intermediate between two well-known models (closed- and open-source systems) in which both the administration and the development costs are shared among the beneficiaries (here Libyan universities under the direction of the Libyan Ministry of Higher Education). The CD-ERP model is a comprehensive and secure version of Cloud-based ERP that is developed jointly (or at least the development is jointly guided) by educational institutes to provide access to current information to all their stakeholders via a range of devices. The administration and development costs are determined in the form of an agreement, where rights and duties are also defined. This model is aimed at both LHE institutes and planners of LHE at the Ministry of Education. With the adoption of cloud-based ERP solutions, it is projected that various universities and colleges will have their business activities computerized in one integrated system as shown in Fig. 2. Based on the model of business activities in HE institutes presented in [31], all of the business activities in HE institutes are classified into educational, research and other activities. This ensures that different types of institutes can join the consortium, regardless of their types and sizes. For instance, research institutes can benefit from ISs dedicated to research activities only or any other activities.

\section{B. The Proposed Model of Collaboration}

This section presents a proposal for the form of collaboration among the members of the consortium based on the findings from the fieldwork in Libya, the international experiences and the literature review. We cannot say whether the proposed model is considered to be outsourcing or insourcing, or whether it is onshore or offshore. In fact, the CD-ERP model is a hybrid one in which the ERP part follows an outsourcing approach, while universities collaboratively develop the system and configure/customize open-source ERP using an onshore approach. Additionally, this model is not simply about traditional forms of collaboration, but rather about developing ISs collaboratively for all the beneficiaries (Libyan universities under the direction of the Libyan Ministry of Higher Education). The approach of collaborative development can be applied to several sectors, such as universities, governments, and the private sector.

\section{Proposed Business Model of the Consortium}

The proposed structure is based on the findings of the study. The business model is summarized in the following points:

1) Type of Consortium: a nonprofit consortium of Libyan universities and research institutions, as well as the Libyan Ministry of Higher Education. The consortium should provide high-performance computing services, such as hardware resources, software application and human expertise.

2) Consortium Structure (Governance Model) - as illustrated in Fig. 3, the consortium consists of two main bodies, namely: the Consortium Council, Board of Executive Directors, and other committees as required, such as a committee of development partners. The consortium council is composed of the rectors/delegates from all of the Libyan educational organizations (public universities, private universities, community colleges or research centers) that have joined the consortium with equal voting rights. The executive directors consist only of the core members, since involving all the members in every detail of the work would slow down development too much.

The board of executive directors is responsible for the development, organization, and management of the 
consortium's activities. Technically, the executive directors have overall control of most of the tasks, such as initiating projects, proposing budgets or generating reports. The final approval of these tasks is, however, the responsibility of the consortium council. This kind of structure ensures that all members would have the right to be involved in decision making.

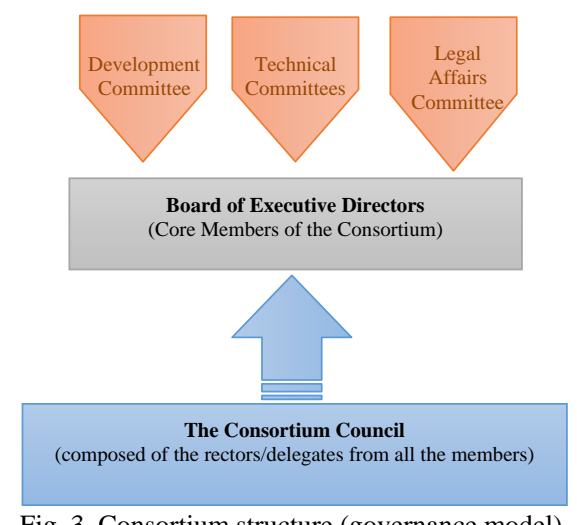

Other committees could be set up as required with a minimum of three committees, namely: Committee of Development Partners, Technical Committee and Legal Affairs Committee. Local companies that wish to take part in the project can be admitted to the Committee for Development Partners. In return, these companies would have priority to become involved in consortium projects. The idea of such a committee comes from the international experiences, e.g. the Kuali project has a similar structure, as well as the findings from the fieldwork in Libya, since all three universities studied host their data in the same local company. The technical committees (e.g. development committee, security committee, networking committee) work as consultancy committees to the executive directors. Finally, the Legal Affairs Committee is to handle compliance with the law, the consortium's statute and the principles of proper management. Each committee may consist of units handling their practical assignments. For example, the development committee may consist of a database unit, applications unit, web development unit, or any other required units.

1) Source of funding - New members must pay a joining fee. Also, annual fees are paid on the basis of the project budget and the size of the member. Members of the Development Partners committee (companies) are also subject to fees and providing IT services to community members. The level of participation of members determines the privileges granted.

2) Goals of the consortium:

a) Developing the ISs needed by the members or at least guiding the development of such ISs.

b) Fully operational ISs to be made available to members, together with technical support covering all subsystems and modules. All the members are to be provided with open source ERP-based integrated systems. These systems will be developed collaboratively in such a way that ERP modules will be customizable to meet an LHE's unique needs. Customization is advised only for processes that are critical, in order to avoid the shortcomings of heavy customization.

c) Source code will be available on-demand to institutions participating in the project, with no limits on end-users or installations. Fees will be based on the size of a member, which will ensure that even small institutions can join the consortium.

d) The system will be multi-tenancy. It will be possible to carry out customization during run-time. The ERP core code will not be modified, which will allow the ERP vendors to run upgrades/updates smoothly.

\section{The Cloud Architecture}

The implementation of CC in HEI faces many challenges, which may vary from technological aspects to national rules and regulations [32]. Based on both the private cloud and educational cloud architecture for HEI presented by [31] and the model of a hybrid cloud presented by [21], the following model of CC is recommended (see also Fig. 4):

1) Each university will possess its own private cloud. The sharing of data on a private cloud with other universities will be banned. Such clouds will store sensitive data and applications relevant only to a particular university. The type of data held in a private cloud will be referred to as a university's internal data, which will comprise all the data that a HEI owns.

2) The Libyan Ministry of Higher Education will own a community cloud, called an "Academic Cloud". Institutional data will be generated by all of the universities participating in this academic cloud. The Ministry of Higher Education will be responsible for ensuring the integrity of these data. Consequently, institutional data will be shared with other universities, as well as being monitored and controlled by the Ministry of Higher Education. This will eliminate duplication and universities' stakeholders, e.g. students and academics will also benefit greatly from avenues for sharing knowledge and research among HEIs.

3) A hybrid cloud will be designed to enable the portability of data and applications between the academic cloud and the private cloud.

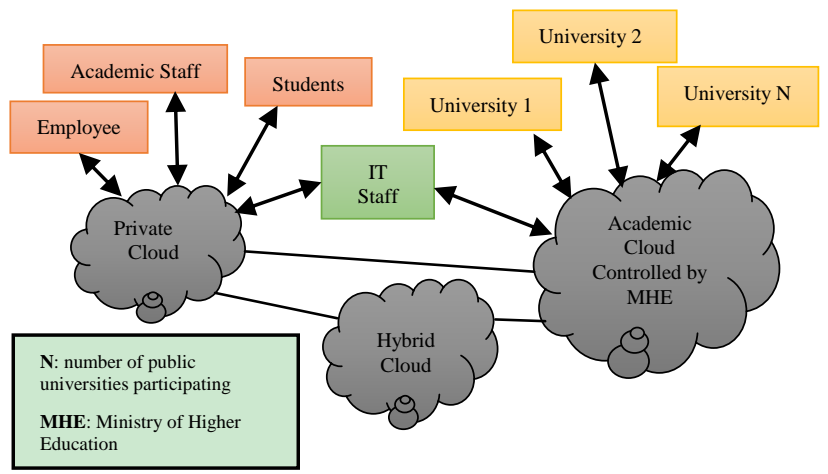

Fig. 4. The CC architecture proposed for the CD-ERP model.

\section{CONCLUSION}

This study has discussed the possibility of introducing the CD-ERP Model in LHE. CD-ERP represents a very promising solution to LHE which offers considerable benefits. This article has proposed a business model for such 
a consortium, together with a Cloud architecture and several other recommendations aimed at ensuring a successful and efficient transformation from the current systems. The model presented is a new approach to system development. The conclusions were based on the results of the case studies. Hence, the generality of these conclusions are unclear. In fact, the case study approach has often been questioned, since it investigates a person, group or organization rather than an entire population. For this reason, the authors tried to include as many case studies as possible, based on the research schedule. However, due to the recent instability in Libya, the authors were unable to include more cases. Regarding the examples of international projects using a similar approach, the authors intended to use a deductive method using data collected from online questionnaires based on the SERVQUAL model. These questionnaires were sent to the administrators of these projects. Unfortunately, none of them responded to the researcher. Thus, the authors suggest that further study of other projects which use a similar approach is required.

\section{RECOMMENDATIONS AND FUTURE WORK}

As presented in Section III, the community-source approach is a successful model, since there are a considerable number of projects across the world that continue to use such models. However, the authors recommend that the implementation of this approach in the Libyan context should be studied through the establishment of a research team that will conduct comprehensive multidisciplinary examinations based on multiple case studies of Libyan HEIs. The authors also recommend investigating the factors of success and failure involved in adopting a CC model and multi-tenancy, including architectures, economic factors, performance, maintenance and scalability. The legal and regulative issues involved with adopting a CD-ERP model should also be studied.

\section{CONFLICT OF INTEREST}

The authors declare no conflict of interest.

\section{AUTHOR CONTRIBUTIONS}

This paper is the end result of an ongoing doctoral dissertation. Tareq S. Almigheerbi is the Ph.D candidate, David M Ramsey is the senior supervisor and leader of the doctoral project, and Anna Lamek is the assistant supervisor. This paper represents the proposed model of the study. The tasks of individual authors are as follows: the research was conducted by Almigheerbi and Ramsey; the data analyzed by Almigheerbi and Lamek; the paper was written and revised by Almigheerbi, Ramsey and Lamek. Finally, all the authors approved the final version.

\section{REFERENCES}

[1] R. Raja and P. C. Nagasubramani, "Impact of modern technology in education," presented at the Conference on Recent Trend of Teaching Methods in Education, Tamil Nadu, India, 4-5 May 2018.

[2] L. Stosic, "The importance of educational technology in teaching," International Journal of Cognitive Research in Science, Engineering and Education, vol. 3, no. 1, pp. 111-114, 2015.
[3] B. Wheeler and J. Hilton. (2012). The marketecture of community, educause review. [Online]. Available: https://er.educause.edu/ /media/files/article-downloads/erm1261.pdf

[4] G. Hanganu. (2008). The community source development model. [Online].

Available: http://oss-watch.ac.uk/resources/communitysource

[5] Cineca. (2019). Cineca project. [Online]. Available: https://www.cineca.it/en

[6] Vertiv. (2018). Vertiv case study. [Online]. Available: https://www.vertivco.com/globalassets/documents/case-studies/vertivcase_study-cineca-it-2018_engb_249727_0.pdf

[7] M. Liu, H. Sean, and Q. Tu, "Toward sustainable collaborative software development: A case in higher education," presented at the Twenty-first Americas Conference on Information Systems, Puerto Rico, 13-15 August 2015.

[8] P. Alves, L. Miranda, C. Morais, and E. Alves, "Proposal of a learning styles identification tool for Sakai virtual learning environment," Computer Science and Engineering, pp. 47-54, 2012.

[9] Sakai. (2019). Sakai project. [Online]. Available: https://sakaiproject.orgx

[10] M. Ignjatovic and S. Jovanovic, "Implementing Sakai open academy environment - Pros and cons," International Journal of Emerging Technologies in Learning (iJET), vol. 8, no. 1, pp. 64-68, 2013.

[11] USOS. (2019). About USOS. [Online]. Available: https://www.usos.edu.pl

[12] M. Czerniak, "Student management information system for Polish Universities at its tenth anniversary," presented at the 16th International Conference of European University Information System, Warsaw, Poland, 23-25 June 2010.

[13] N. Cuni, "Scientific outputs: Integration and unification of Catalan CRIS information systems," Procedia Computer Science, vol. 33, pp. 278-283, 2014.

[14] Sigma. (2019). Sigma project. [Online]. Available: http://www.sigmaaie.org

[15] M. F. Paulsen, "Online education systems in Scandinavian and Australian universities: A comparative study," The International Review of Research in Open and Distributed Learning, vol. 3, no. 2, pp. 2-11, 2002.

[16] FS. (2019). Forsiden UiO. [Online]. Available: http://www.usit.uio.no

[17] J.-F. Desnos, "A national data warehouse project for French Universities," 2018.

[18] Feasibility-study, "Final report, Feasibility study: Modernisation of student information systems, by University of Tampere," 2012.

[19] HisinOne. (2019). [Online]. Available: https://www.his.dex

[20] U. Hubner, I. Duda, M. Merz, D. Natusch, and H.-D. Weckmann, "HISinOne - Development and early adoption partnerships," presented at EUNIS 2008: The 14th Congress in a Series of Conferences within the Framework of the European University Information Systems Organization, Denmark, 24-27 June 2008.

[21] R. M. Almajalid, "A survey on the adoption of cloud computing in education sector, Cornell University Library," 2017.

[22] Monarch, "Open-source learning management systems: Sakai and moodle," Whitepaper, 2010.

[23] M. W. A. Bakeer, "ICT utilization in Libyan Universities: A report on case study research," presented at the Sixth International Conference on Creative Content Technologies, Venice, Italy, May 25-29, 2014.

[24] A. Rabaa'i, "Identifying critical success factors of ERP Systems at the higher education secto," presented at Third International Symposium on Innovation in Information \& Communication Technology, Amman, Jordan, 15-17 Dec 2009.

[25] S. Rani, "A review of ERP implementation in higher education institutions," International Journal of Advanced Research in Computer Science and Software Engineering, vol. 6, no. 6, pp. 542-545, 2016.

[26] S. V. Shrivastava and H. Date, "Distributed agile software development: A review," Journal of Computer Science and Engineering, vol. 1, no. 1, pp. 10-17, 2010

[27] C. Gutwin, R. Penner, and K. Schneider, "Group awareness in distributed software development," presented at the 2004 ACM conference on Computer supported cooperative work, Chicago, Illinois, USA, 6-10 Nov 2004.

[28] C.-P. Bezemer and A. Zaidman, "Challenges of reengineering into multi-tenant SaaS applications," Software Engineering Research Group Delft University of Technology, Technical Report Series, Delft, Netherlands, 2010.

[29] J. Kabbedijk, M. Pors, S. Jansen, and S. Brinkkemper, "Multi-tenant architecture comparison," presented at the European Conference on Software Architecture, Vienna, Austria, 25-29 August 2014 
[30] L. Zornada and T. B. Velkavrh, "Implementing ERP systems in higher education institutions," presented at 27th Int. Conf. Information Technology Interfaces ITI, Cavtat, Croatia, 20-23 June 2005.

[31] S. Mathew, "Implementation of cloud computing in education - A revolution," International Journal of Computer Theory and Engineering, vol. 4, no. 3, pp. 473-475, 2012.

[32] G. Kiryakova, "Cloud computing — A necessary reality in modern education," International Journal of Scientific and Research Publications, vol. 7, no. 4, pp. 158-164, 2017.

Copyright $(9) 2020$ by the authors. This is an open access article distributed under the Creative Commons Attribution License which permits unrestricted use, distribution, and reproduction in any medium, provided the original work is properly cited (CC BY 4.0).

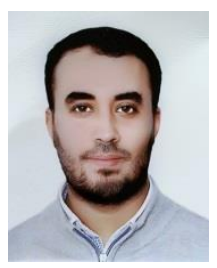

Tareq Salahi Almigheerbi was born in Tripoli/Libya, 1982. In 2004, He obtained a bachelor's degree in computer science from the University of Tripoli, Libya. In 2008, the author obtained a master of science degree in information technology from the Faculty of Information Technology and Quantitative Science, Universiti Teknologi Mara Malaysia (UiTM) "Mara University of Technology", Shah Alam, Malaysia. Currently, he is working on his $\mathrm{PhD}$ at Wrocław University of Science and Technology.

The author's major fields of study are information systems, community-source, ERP and software development. Since 2012, he has been working as a full-time lecturer at the Department of E-commerce, Faculty of Economics \& Political Sciences, University of Tripoli. He has developed many offline and online systems. Mr. Almigheerbi has worked as the Department Head of the Office of Information and Documentation, at the Faculty of Economics, University of Tripoli, Libya. Moreover, he was a member of ICT development community at the University of Tripoli.

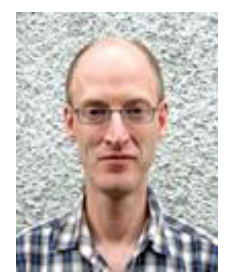

David M. Ramsey was born in Cardiff, UK in 1967. In 1990 he obtained a bachelor's degree in mathematics from the University of Bristol, UK and in 1994 obtained a $\mathrm{PhD}$ in statistics from the same institution. In 2005, he obtained a higher degree in economics from Warsaw School of Economics, Poland. David Ramsey's main fields of study are decision theory, in particular game theory, probability and statistics. He has worked at the Faculty of Computer Science and Management, Wrocław University of Science and Technology, Poland since 2012, where he was promoted to the position of University Professor in 2016. He has also worked at the University of Limerick, Ireland and the University of Bath, UK. His current research interests include behavioral economics, dynamic games and applications of decision theory to the management and biological sciences. Prof. Ramsey is a member of the International Society of Dynamic Games and the Polish Economic Society.

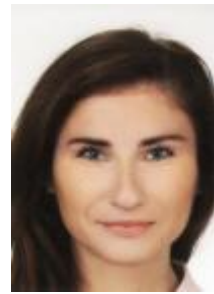

Anna Lamek is an assistant professor in the Operations Research Department at the Faculty of Computer Science and Management, Wrocław University of Science and Technology. In 2009, she obtained a master's degree with a subject titled "Information Technology in Management" at the Faculty of Computer Science and Management, Wrocław University of Science and Technology. In 2014, she graduated from Wroclaw University of Technology and received her $\mathrm{PhD}$ in Management. Her research interests are as follows: forecasting, economics, decision-making, big data, IoT, game theory, fair division procedures, ERP systems. 